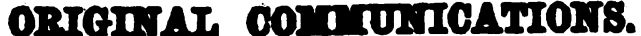

\section{THREE LECTURES ON THE CORRELATION OF PSYCHOLOGY AND PHYSIOLOGY.}

By DANIEL NOBLE, M.D., Visiting Physician to the Clifton Hall Retreat, near Manchester.

[Dolivered at the Chatham Street School of Medicine, Ianchester, June 1851.]

\section{InCTORI II.}

OV BMOTIOXAL BBNBIBILITY, AND ITE REACTION8.

Thine is a sensibility more elevated in the psychical scale than either external sensation or the physical appetites; I xefor to that all-pervading sense of bodily existence which the German psychologists have named Cancesthesio-general feeling, and sometimes self-feeling (Selbst-gefihl). This sensibility connects itself, apparently, with the peripheral termination of nerves throughout the whole body, but more particularly of those supplying the thoracic and abdominal viscere.

It would seem to locelise itself in an especial manner sbout the precordial region. It will best be indicated peychologically, by use of the popular phraseology, the spirits. Under ordinary circumstances, this sense-consciousness is that of bodily contentment-tranquil spirits. When it is exalted, we are said to be in high spirits, glad at heart, joyous; we feel as if there were a spring in every limb; we are light as a feather. When it is depressed, low spirits are experienced; we are heary and dull, and inapt for exertion. Acutely felt, it is emotion. These several states of the animal spirits, so designated, may result from purely physical causes, and, in their origin, be quite irrespective of thought. All persons have their general sensibility more or less modified by atmospheric states and by conditions of the viscera. Refer to the recollections of some brilliant morning in early summer; how cheering the experience. Go back in memory to the gloomy days of a damp Norember, and recal the dispiriting influence of its fogs and its mists. The relation between visceral states and the animal spirits is the theme of perpetual recognition. Who has not experienced the importance of a sound digestion to the tranquillity of his feelings?

This general sensibility has sometimes been confounded with common sensation. A moment's reflection, however, upon the respective phenomens should demonstrate their essential difference. Emotional sensibility maintains no sort of uniformity with that which is tactile. On the contrary, when the former is greatly elevated, the sense of touch is sometimes paralysed. Witness the emotional effects observed in heroic enthusiasm, and how merely sensational impressions are disregarded under such circumstances. And the tactile sensibility may be most acute, when there is no emotional excitement whatever. When this latter has place to a great extent, a mitigation is often obtained by superinducing the ordinary sense of bodily pain. In that extraordinary epidemic of the middle ages, the dancing mania, so admirably described by Hecker, the paroxysms were most effectually interrupted by blows and kicks, which persons were always found ready to administer; the operation of these being to bring about sensational, and thereby to weaken emotional, sensibility. During the periods of excitement, the external senses were literally sealed. "While dancing," says Hecker, "they neither saw nor heard, being insensible to external impressions through the senses."

The action of particular medicines suggests a physiological distinction between sensation and emotion. Opium and other such drugs, whilst they depress tactile sensibility, exalt that which is emotional.

Now for the ccencesthesis, or self-feeling, or the emotive sense, as it has been varionsly designated, there must, I apprehend, be proper ganglia within the encephalon. Dr. Carpenter is with those who refer this function to the same centren as those of the external senses, and particularly to the ranglionic centres of common sensation. He catretion the opinion, with some other phyriologiots, that the poiturior cerebral genglie commonly alled the optic thalami, are for the fulfilment of this latter office; and that the anterior ganglia, the corpors striate, are most likely the source of the respondent movements. I have myself proposed, in the last lecture, that the inferior ganglia of the cerebellum constitute the encephalic centres of common sensation; and I believe that the optic thalami and corpora striata-the corresponding ganglis of the cerebrum-form the specinal region of emotional sensibility.

Comparative anatomy would seem, in some measure, to favour this opinion. In the lower forms of vertebrated creatures, the analogues of the corpora striats and optic thalami are exceedingly large in relation to the rest of the encephalon. In fishes, these structures are voluminous, whilst cerebral hemispheres, in some instances, are not discoverable, and, in many others, are purely rudimentary; and, so far as we can reason concerning the psychology of fishes, wo should infer that some inward sensibility, rather than external sensation, principally determined their numerous morements, these being subservient to their self-conservation, and having but little relation, apparently, to outward phenomena. In this view of the case, we should deem their chief sensibility to be emotional in its nature, rather than tactile; but, of course, not to the exclusion of this latter, though in the watery element there would appear to be no predominant need for it.

The encephalon of birds does not show quite so predominant a size of the ganglia under consideration, the cerebral hemispheres being more developed; it seems reasonable, however, to refer the instinctive and habitual movements of birds in a great degree to sensibility of an emotional character.

When we come to the mammalia, and the higher wo ascend in the scale, the entire conscious life of the different creatures becomes less and less a mere sensibility, and more and more an intelligence. And when we arrire at Man, the highest forms of this latter are attained; and emotion, as an independent and primary source of movement and conduct, sinks to its lowest point, abundant though it remain.

These circumstances correspond with the relation, as to volume, which the hemispheres of the brain and the cerebral ganglia-optic thalami and corpora striata-maintain towards each other, throughout the animal kingdom. The lower we descend in the scale, the more do these latter structures go to make up the encephalon; and, in the samo correspondence, the more do the actions appear to spring from some instinctive, unintelligent source-the emotive principle of "self-feeling", most likely.

Vivisections practised upon the nervous centres are of no great value in determining function, excepting in so far as they corroborate an inference otherwise obtained. It was found by Dr. Budge that irritation of the corpora striata and corpora quadrigemina-these latter being immediately contiguous to the optic thalami-excited vivid peristaltic movements.* A like effect is a very ordinary result of sudden and intense emotion.

The evidences, also, of morbid anatomy, in inquiries of thig gature, are but little conclusire. Andral's collection of instances in which there was found extravasation into the optic thalami, do not, however, exhibit any corresponding lesion of tactile sensibility, a result which might have been anticipated, with unusual frequency at least, if the structures had been the ganglia of common sensation. Perversions of the emotive sense, as distinguishable from external sensation, have had too little account taken of them, for the existing records of morbid anatomy to be made available with reference to the hypothesis I have myself advanced.

In the autumn of last year, I assisted at the post mortem eramination of a case, in which, during life, there had been unusual manifestation of emotional sensibility, without disturbance of the intellect. The right corpus striatum alone afforded signs of morbid change. Notes were taken at

- London Modical Gezette, vol i, for 1839-40. 
the ting by my friend, Mr. Faleh, of thin city, who had athed the patient; and from these I cite the following coovint. James Connor, aged 66, was a man of temperate bibits, and one who, through life, had enjojed good health and spirits, until within two jesrs of his death. At this period, the became involved in pesuniary difficulties, and pervopon became low-epirited and somewhat unsocial. He continued to follow his business, howerer, as usual. Two months before his death, he embarked the remains of a small capital in some speculative undertaking, which issued in complete and immediate failure; a circumstance which very seriously aggravated his mental depression. $\Lambda$ fortnight after this catastrophe, he was seized with slight parralysis of one arm, which, however, disappeared spontaneously in about a week. It returned in a few days with increased severity, hemiplegia, indeed, shewing itself. The affection, to some extent, involved both sensation and motion; and there was also, inability to articulate with any distinctness. "At this time," says Mr. Walsh, "I was sent for. I found his general health not bad. Though both motion and sensation were affected considerably. neither were abolished; the tongue appeared to be the most affected, especially when efforts were made to converse. There was some impairment of vision, but the pupil showed no change. His intelligence was undisturbed, and but little enfeebled. Fis emotional excitability was remarkable, the most trifling circumstance being sufficient to provoke it. When I visited him, he was literally overjoyed; and, when I took my leave, he eoould grasp my hand and burst into tears. At my last visit, twenty-six hours before his death, there was but little change in his general condition, except that he was weaker; still he was able to be up and out of bed. When I left him on this occasion, the emotion displayed was truly distressing. He rested badly the ensuing night, moaning much at intervals; next morning, he became drowsy, and towards noon was slightly convulsed. He expired at 6 P.M., Nor. 18th, 1853. On examining the head, eighteen hours after death, the ressels of the scalp were cmpty; the sub-cutaneous tissue was pallid; the membranes of the brain were healthy, the vessels unloaded, and the sinuses empty; the superior aspect of the cerebrum was natural, the convolutions a little flattened probably. On raising up the whole encephalon, a considerable quantity of serum slightly tinged with blood was found at the base. The consistence of the cerebral substance was good, and on slicing it very few puncta vasculosa rere observable. Fluid, similar to that discovered at the base, occupied the ventricles also, and in considerable quantity. The choroid plexuses were not congested; but, over the right corpus striatum, there ramified several large vessels. On cutting into this structure, the grey colour woas found deepened, and blood flowed from a number of points, forming in these respects a striking contrast to its fellow on the opposite side, as indeed to all the rest of the encephalon. The cerebellum was quite natural."

The following communication with which I have been kindly favoured by Dr. Fripp, of London, comprises particulars of a case very analogous to the one just related :"A gentleman intimately known to me, one who possessed considerabiy more than owiuing p.? ments, and one whose strength of purpose and firmness were among his most distinguishing characteristics, was reized, *ithout previous warning, with forgetfulness of words, in the midst of a very active career involving ceaseless occupation of mind and body. Perfect quietude and gentle medication very speedily succecded in restoring this failure, and he appeared well again. But it was impossible to restrain his ardent desire for activity by the most explicit announcement of what this symptom in all probability indicated. In about two months, sudden and complete confusion of memory occurred, producing the strangest jumbling together of true and false that I remember ever to have witnessed. This was followed by partial paralysis of the left arm and facial muscles: and, at the same time, great emotional excitability shewed itself. It is worthy of remark that apart from the affection of memory of recent erents-which itself underwent considerable improvement- there was no impairment of intelloet to be recognied. His con topics and on whatover appentul chiefy to the reasoning powers was as clear and fercible as over: and his quiet indomitablenees of will showed iteelf repentedly in many cha racteristic ways. Yet he was at this rexy time, and whilst the memory was improving, moved to tears - a thing quite etrange to him by the diabtest ococrion of foding, even by a bivil word, and the right of a friend. Lfter ome considerable apperent amendmont, and on secomt of reppplication to various objects of former intersat and occupation, which it surprises me now to think of as possible in such a condition, he suddenly became apoplectic, and died within ten months of the very first intimation of disease.

"Besides evidence of some meningo-opheditis on the surface chiefly on the right side, the main result of the pout mortem inspection was the disclosure of a large mass of dirty grey softened cerebral substance in the central part of the right hemisphere on a level with the corpess callosum, and principally over the posterior pert of the corpus striatum. This portion of the corpus striatum was itolf softened, and as though corroded, and liquefied matter fillod the descending corner of the corresponding lat sral ventricle. The thalamus was sound; and also every other part of the encephalon appeared to be, after a most rearching examination.

"What struck me as a point of connexion between this case and jour views of the function of different parts of the. encephaion, was, I need hardly say, the prominent development during its progress of emotional exeitability, and the damaged corpus striatum, with perfect integrity of the meso-cephale, apparent after death. But to enable you to judge more fairly bow far this connexion deserves to be regarded as essential, I have briefly stated all the other leading particulars of the case."

Certain nations are characterised more than others by emotional sensibility; the Irish, for example, more than the Seotch. Women are, in this respect, more remarkable then men. It would be interesting to compare the relative dorelopment of the optic thalami and corpora striats in the respective instanees.

Emotional sensibility produces its own reactions upon the muscular system, independently of the movements denominated consensual. A cheerful countenance, with a light elastic step, denotes a pleasurable feeling; whilst a sorrowful, anxious look, with heavy tread and measured gait, indieates painful and depressed emotion.

In certain morbid states, emotional sensibility will react upon museles that are paralysed to volition and sensory impressions. In laughter and weeping, facial paralysis becomes disguised, sometimes, for the moment.

Probably the most striking and conopierous phenomenon, consensual as crdinarily occurring, is formed by the ejacenlatio seminis. But I had, some jears ago, a patient-a gentleman in good general health, and in the meridian of life-in whom there was impotence of erection and insensibility to the allied local impression; yet, under the influence of emotion-in attempted coitus the seminal effusion would take place.

Such facts, I conceive, corroborate the view which I have taken, that sensation and emotion have separate and distinet centres in the encephalon.

\section{$\int_{1}$ \\ ON THE PATHOLOGY AND TREATMENT OF LARYNGO-TRACHEAL INFLAMMATION.}

\section{By ROBFiTT TURNER, M.D.}

\section{[Continued from page 591.]}

Ths bearing of these pathological speculations on the therapeutics of laryngo-tracheal inflammation may next be considered. Their general tendency undoubtedly is to inculcate promptitude and dingence in the use of remedial measures, as the sole conditions on which success is attainable. We possess resources by which, if employed energetically at the onset of the disease, the fons et origo mati mas be directly combated, and the speedy arrestment of 